\title{
Resources for Educating, Training, and Mentoring All Physicians Providing Palliative Care
}

\author{
James Downar, MDCM, MHSc (Bioethics), FRCPC
}

\begin{abstract}
This article presents a rapid review of the published literature and available resources for educating Canadian physicians to provide palliative and end-of-life care. Several key messages emerge from the review. First, there are many palliative care educational resources already available for Canadian physicians. Second, the many palliative care education resources are often not used in physician training. Third, we know that some palliative care educational interventions are inexpensive and scalable, while others are costly and time-consuming; we know very little about which palliative care educational interventions impact physician behavior and patient care. Fourth, two palliative care competency areas in particular can be readily taught: symptom management and communication skill (e.g., breaking bad news and advance care planning). Fifth, palliative care educational interventions are undermined by the "hidden curriculum" in medical education; interventions must be accompanied by continuing education and faculty development to create lasting change in physician behavior. Sixth, undergraduate and postgraduate medical training is shifting from a time-based training paradigm to competency-based training and evaluation. Seventh, virtually every physician in Canada should be able to provide basic palliative care; physicians in specialized areas of practice should receive palliative care education that is tailored to their area, rather than generic educational interventions. For each key message, one or more implications are provided, which can serve as recommendations for a framework to improve palliative care as a whole in Canada.
\end{abstract}

Keywords: competency-based education; education; medical; palliative care; review

\section{Introduction}

$\mathbf{N}$ UMEROUS REPORTS have highlighted the importance of improving education for physicians in palliative and end-of-life care in Canada. ${ }^{1-3}$ This article provides an overview of the resources required to ensure that palliative care education of physicians in Canada achieves the highest standard possible. This rapid review is organized into key concepts that are meant to summarize the main lessons from the literature. At the end of each section, one or more implications are identified.

\section{Methods and Scope}

This is a rapid review of articles and resources identified by a literature search (described previously), as well as other resources and recently published systematic reviews and meta-analyses known to the author.

\section{Results and Conclusions}

1.0. There are many palliative care educational resources already available for Canadian physicians.

There have been a number of efforts in Canada to develop a palliative care curriculum or comprehensive set of competencies for all physicians and physicians in training. These include (but are not limited to) the following:

- Learning Essential Approaches to Palliative Care (LEAP) ${ }^{4}$

- Educating Future Physicians in Palliative and End-ofLife Care (EFPPEC), ${ }^{5}$ and the

- Ian Anderson Continuing Education Program in Endof-Life Care. ${ }^{6}$

Intensive learning courses are also available such as that offered by the Victoria Hospice. ${ }^{7}$ There are online resources that feature practice guidelines such as the Canadian Virtual Hospice $^{8}$ and Cancer Care Ontario's Palliative Care tools. ${ }^{9}$ There are

Division of Palliative Care, Department of Family and Community Medicine and Interdepartmental Division of Critical Care Medicine, Department of Medicine, University of Toronto, Toronto, Ontario, Canada.

Accepted August 30, 2017. 
also courses and resources available internationally to Canadian physicians, such as Education in Palliative and End-of-Life Care (EPEC) ${ }^{10}$ In short, we already have many palliative care educational resources available to Canadian physicians and efforts to develop new generic palliative care resources are unlikely to improve substantially on what already exists.

A great deal of human effort is being spent to develop palliative care educational material that essentially duplicates or at best is a minimal improvement over existing resources. This inefficient process is fueled by a system that rewards academic physicians for their productivity and "impact." Simply put, successful academic physicians are those who develop a resource and then convince others to use it.

However, the knowledge base of palliative care evolves slowly and does not justify the routine development of new material from scratch. A more efficient system would be to have one or two standardized curricula. This would allow academic physicians to put their efforts toward broad dissemination rather than duplication, much as is done for advanced cardiac life support training. Academic institutions can encourage this by incentivizing palliative care teaching and recognizing the special impact of this activity, rather than just the development of new material.

Implication: Educational efforts should be focused on broad dissemination and uptake of existing resources, rather than generating new resources.

\subsection{The many palliative care education resources have not translated into physician training.}

Canadian physicians are not being adequately trained in palliative care. Ten of the 17 Canadian medical schools provide fewer than 10 hours of palliative care in their undergraduate curriculum. ${ }^{11}$ Postgraduate trainees generally report low or moderate levels of comfort providing end-oflife care and often find that they are unsupervised for important end-of-life procedures such as family meetings. ${ }^{12}$

Palliative care rotations are not mandatory except in a very few training programs and many postgraduate trainees are unable to complete elective rotations in palliative care because of limited availability. ${ }^{11}$ Practicing physicians were often trained in an era or location where palliative care training was not available at all and they have many competing demands for their limited hours of continuing medical education. The main gap in palliative care education is not that educational resources are unavailable; the gap is that the existing resources are not being accessed sufficiently.

Implication: Academic institutions should properly recognize and incentivize palliative care teaching for current and future physicians.

3.0. Some palliative care educational interventions are inexpensive and scalable; others are costly and timeconsuming. We know very little about which palliative care educational interventions impact physician behavior and patient care.

The most common conceptual framework for assessing the impact of an educational intervention is the Kirkpatrick framework. ${ }^{13}$ This framework describes four levels of impact:

- the reaction of the learner (level 1);

- the knowledge of the learner (level 2);
- the behavior of the learner in a clinical environment (level 3); and

- patient-level outcomes (level 4).

Medical educators and researchers generally value higher levels of impact, and studies that look at levels 3 and 4 are generally considered more academically rigorous. Unfortunately, such studies are rare. One systematic review of over 10,000 articles on simulation-based medical education found only 50 that reported patient outcomes. ${ }^{14}$ None of the 50 studies was relevant to palliative care.

Among the palliative care educational studies identified in our literature search, virtually all reported learner reaction and knowledge outcome levels 1 and 2. This dearth of higher level data makes it challenging to identify which interventions are most effective or how to improve a standardized curriculum over time.

We should recognize that measuring level 3 and 4 impact is generally costly and requires a large number of learners. In Canada, educational research grants are typically very small. Those offered by the Royal College of Physicians and Surgeons are $\$ 25,000$ per year. This usually precludes a large or logistically complicated study.

To fill this evidence gap, more resources need to be given to supporting educational research and academic institutions need to support the conduct of educational research. Educational interventions should be broadly seen as quality improvement initiatives aimed at knowledge adoption and they should be evaluated on that basis. The first step in a quality improvement initiative is to gather data about current performance. So, if we want to evaluate the effectiveness of palliative care education, academic hospitals need to create a better infrastructure for the routine assessment of the quality of end-of-life care in the clinical environment, including symptom management and advance care planning.

Implication: Academic institutions need to create and support an infrastructure for the routine assessment of the quality of end-of-life care in the clinical environment, including symptom management and advance care planning, to allow better assessment of training effectiveness.

4.0. Two palliative care competency areas in particular can be readily taught: symptom management and communication skill (e.g., breaking bad news and advance care planning).

Symptom management is a broad competency, but it includes elements of knowledge that can be assessed and improved using different methods. Several authors have shown that completing a palliative care rotation improves trainee comfort and skill in symptom management. ${ }^{15,16}$ Others have shown that a one- to two-day workshop can improve knowledge and comfort with providing palliative care. ${ }^{17}$ Some have demonstrated the effectiveness of integrating longitudinal palliative care curricula or distance learning into postgraduate medical education for improving comfort and knowledge among trainees. ${ }^{18-23}$ Some have shown that web-based modules are effective for improving knowledge and attitudes about palliative care ${ }^{24,25}$ and one study showed an improvement in symptom control. ${ }^{26} \mathrm{We}$ and others have shown that even a simple pocket reference tool can be effective for improving symptom control knowledge and comfort levels among 
trainees. $^{27,28}$ In most cases, there is no evidence to indicate whether these interventions impact patient care.

Communication skills can be learned and improved with training. As mentioned above, studies of educational interventions aimed at communication skills rarely look at patientlevel outcomes. A recent systematic review and meta-analysis could not identify enough studies to form any conclusion about the effects of these interventions on patient care. ${ }^{29}$

Berkhof et al. analyzed 11 systematic reviews of interventions aimed at teaching communication skills to physicians. ${ }^{30}$ Although the authors looked at all types of communication skills and many of the reviews included studies that only looked at levels 1 and 2 impact, they were able to identify specific training strategies that appear to be more effective. These include the following:

- learner-centered, deliberate practice approaches in combination with instruction (didactic elements);

- workshops that last at least one day;

- role playing with simulated or real patients;

- feedback; and

- small group discussion.

In particular, feedback was felt to be associated with improved patient satisfaction with communication.

Some specific studies illustrate the successes and challenges in this research field. Fallowfield et al.'s landmark study from 2002 evaluated the impact of a three-day multimodal communication course on specific communication behaviors in oncologists. ${ }^{31}$ The study enrolled a large number of physicians $(n=160)$ and found that the course was effective at increasing the incidence of many (but not all) desirable behaviors in the clinical environment. Some behaviors were simply too rare to show statistical improvement even in a study of this size. ${ }^{31}$

Bays et al. integrated communication training about serious illness into an academic program for medical residents and nurse practitioners over 8 half-day sessions. They found that this training improved communication behavior in a simulated scenario. ${ }^{32}$ However, when this same approach was used in a larger study $(n=472)$, the intervention did not improve patient-reported outcomes (level 4) and was actually associated with a small increase in depressive symptoms. ${ }^{33}$

We studied a shorter, four-hour multimodal workshop featuring the same educational elements in 94 first-year medicine trainees, and although we found a significant improvement in communication skills compared with controls, this improvement disappeared in a multivariable regression analysis adjusting for baseline differences. ${ }^{34}$

Implication: Effective communication training can be timeconsuming and costly. It requires support (i.e., time and resources) from all stakeholders.

5.0. Palliative care educational interventions are undermined by the "hidden curriculum" in medical education. These interventions must be accompanied by continuing education and faculty development to create lasting change in physician behavior.

Although there is some evidence to guide us when it comes to designing educational interventions, we need to be realistic about the limited effect of workshops and lectures alone on patient care. Improving palliative care is as much about changing medical culture as it is about teaching skills and knowledge.

There is a very strong hidden curriculum in medical practice and trainees are routinely exposed to more senior physicians who oversimplify goals-of-care discussions (e.g., "If your heart stops, what do you want us to do?") and standardized order sets with inappropriate analgesic orders.

Trainees often learn communication techniques for goalsof-care discussions by watching their supervising physicians, ${ }^{35-37}$ and so, efforts to teach at the undergraduate and postgraduate levels will be more effective if accompanied by teaching for the attending physicians who will be supervising them in the clinical environment. ${ }^{38}$

Academic physicians need to teach and also model the behaviors that we expect trainees to learn. They also need to be formally trained in assessment and feedback to facilitate the learning of palliative care competencies. ${ }^{39}$ Veloski et al. reviewed the literature on assessment and feedback, and found that feedback was more likely to be effective when provided by an authoritative source over a prolonged period of time. ${ }^{40}$ This underscores the importance of ensuring that palliative care teaching and feedback must carry over into the clinical environment workshops and lectures alone are insufficient.

However, there are many factors that impede such feedback, including a lack of faculty training, limited time and opportunity for observation, and increasingly brief relationships between faculty and trainees. ${ }^{41}$

We will need to find innovative approaches to encourage continuing education in palliative care and faculty development in teaching palliative care. Steinert et al. conducted a systematic review of the literature around faculty development initiatives designed to improve teaching effectiveness. They found that these initiatives were generally well received by faculty and resulted in significant improvements in selfreported behaviors. ${ }^{42}$

Features of effective faculty development interventions include experiential learning, giving feedback, and the use of diverse educational methods. ${ }^{42}$ Peer-to-peer support and mentorship approaches are a key feature of effective faculty development initiatives and a peer-to-peer continuing education program was successful for improving confidence and knowledge among practicing physicians in British Columbia. ${ }^{43}$

Most recently, the "Quality End of Life Care for All" (QELCA) program in the United Kingdom has allowed practicing physicians to experience hospice care through a five-day clinical immersive experience. They then bring that experience back to their own practices as part of a longitudinal learning project. ${ }^{44}$ Unfortunately, as with most educational studies, few have measured the effect of faculty development initiatives on student performance in the clinical environment.

Continuing education and faculty development could also be formally incentivized. The Maintenance of Certification programs of the Royal College of Physicians and Surgeons and the College of Family Physicians of Canada now requires members to complete different types of Continuing Professional Development activities, including knowledge and performance assessment. Some of these activities could include training and feedback around communication skills. In fact, the American Board of Medical Specialties specifically mandates assessment and development activities in six competencies, one of which is "Interpersonal and Communication Skills." 45 Although such an approach does not necessarily ensure that all development 
activities will be of high quality, it does send a message about the importance of this area of competence.

Implication: Academic hospitals and faculties of medicine must encourage and incentivize faculty development in palliative care training and feedback for all teaching faculty. Implication: All stakeholders should support innovative and effective approaches to palliative care professional development. Both certifying colleges should consider mandating professional development activities in palliative care.

6.0. Undergraduate and postgraduate medical training is shifting from a time-based training paradigm to competency-based training and evaluation.

Historically, medical training has been based on time spent in a supervised clinical environment. The assumption has been that if trainees spend the required number of years in a program (including a specified number of months on specific rotations), they will acquire the competencies required to practice. Trainees are assessed in a summative manner at the end of each rotation by their supervisors, and they undergo a formal assessment by examination (written and/or oral) at the end of their training by a certifying body (e.g., the College of Family Physicians of Canada or the Royal College of Physicians and Surgeons of Canada).

Medical education in Canada is undergoing a shift toward competency-based training and assessment. Under this new paradigm, there will be a greater emphasis on repetitive formal assessment, focused feedback, and a determination about when the trainee is competent to perform a given task.

Palliative care is well positioned for this paradigm shift Jurisdictions from around the world have developed their own competence frameworks for palliative care. ${ }^{46}$ In Canada, a national effort led by Dr. Jeff Myers has led to the development and validation of a set of 12 Entrustable Professional Acts (EPAs) that define and distinguish palliative care. ${ }^{47}$ These EPAs are now being incorporated into training programs across the country. They must be accompanied by faculty development initiatives and there are typical challenges involved in applying a new framework of competency-based assessment and training. However, the shift to a competency-based framework will ultimately help address the problems created by the hidden curriculum by incorporating more attending physicians into training and assessment of palliative care competencies. It will also ensure that the desired behaviors are occurring in the clinical environment, rather than simply on a survey or a test. These competencies can also be assessed in practicing physicians, allowing more quality assessment and improvement outside of the academic setting.

Implication: Academic palliative physicians should adopt a competency-based training and evaluation paradigm, and institutions should consider mandating faculty development work to support competency-based training and evaluation.

7.0. Virtually every physician in Canada should be able to provide basic palliative care. Physicians in specialized areas of practice should receive palliative care education that is tailored to their area, rather than generic educational interventions.

A recent Ipsos poll indicates that most Canadians want a specialist to provide their end-of-life care. Considering that more than 250,000 Canadians die every year, and there are only 500 members of the Canadian Society of Palliative Care Physicians, this is clearly not possible. However, it is reasonable to expect that every dying Canadian should receive care from a physician with expertise in palliative care. Most patients will not have complex symptom needs and should not need a specialist palliative care provider for primary palliative care, the same way that most patients do not need a cardiologist to manage their hypertension.

Palliative care must be seen as the responsibility of all providers, not just palliative care specialists. To that end, all physicians in training should learn palliative care competencies and many training programs should consider mandatory training rotations in palliative care. Currently, the only subspecialty or certificate programs recognized by the Royal College of Physicians and Surgeons that have a mandatory palliative care rotation are medical oncology and radiation oncology. Such training would be equally relevant to subspecialty trainees in cardiology, respirology, nephrology, gastroenterology, geriatrics, and general internal medicine, as well as the Diploma programs in hepatology, advanced heart failure and cardiac transplantation, and solid organ transplantation. The College of Family Physicians of Canada mandates rotations in obstetrics and gynecology for all future family doctors, even though only a small percent will perform obstetrics. The same college does not mandate rotations in palliative care, even though virtually all family physicians will care for patients with life-limiting illnesses.

Although finding No. 1 argued against the need for new generic training material, specific areas of medicine may benefit from the adaptation of existing material to suit their context. Much of palliative care knowledge and practice stems from the treatment of cancer patients, and there are important differences between cancer and noncancer illness. ${ }^{48}$ We cannot simply apply a cancer-derived model to all situations, and some practice types (e.g., intensive care) call for specific skills that may not be found elsewhere. In particular, the LEAP curriculum is being adapted to different contexts, such as the emergency department and long-term care. This process should be encouraged. Furthermore, while interprofessional education should remain a priority, we should recognize that the roles, learning needs, and learning priorities of nurses, physicians, and other allied health professionals may be different. ${ }^{49}$ A one size fits all approach may need to be tailored for certain tasks.

Implication: Both certifying colleges should include palliative care competencies in all fields of medicine and should include palliative care rotations in the subspecialty training requirements for subspecialties where palliative care is particularly relevant.

Implication: Palliative care education should be tailored to meet the needs of physicians in specialized areas of practice.

\section{Acknowledgments}

The author acknowledges the contributions of the Palliative Care Matters Research Support Team: Sharna Polard and Roger Salus for library services and literature searching; Heather Stiles and Michelle Sims for overall research coordination and assistance; and Lisa Weisgerber for literature screening, literature review, and project support. 


\section{Author Disclosure Statement}

No competing financial interests exist.

\section{References}

1. Canadian Medical Association: Palliative Care: $\mathrm{CMANa}$ tional Call to Action. Ottawa, ON: Canadian Medical Association, 2015.

2. Carstairs S: Raising the Bar: A Roadmap for the Future of Palliative Care in Canada. Ottawa, ON: The Senate of Canada, 2010.

3. Carstairs S, Beaudoin G: Quality End-of-Life Care: The Right of Every Canadian. Ottawa, ON: Senate of Canada, 2000.

4. Learning Essential Approaches to Palliative Care (LEAP): http://pallium.ca/professional-development/leap-2/. (Last accessed September 20, 2016).

5. Educating Future Physicians in Palliative and End-of-Life Care: www.afmc.ca/pdf/Educating Future Physicians in Palliative and End-of-Life Care-e.pdf. (Last accessed September 17, 2016).

6. Ian Anderson Continuing Education Program in End-ofLife Care: www.cpd.utoronto.ca/endoflife/Modules.htm. (Last accessed September 24, 2016).

7. Victoria Hospice Courses: www.victoriahospice.org/healthprofessionals/courses. (Last accessed September 20, 2016).

8. Canadian Virtual Hospice for Professionals: http://virtual hospice.ca/en_US/Main+Site+Navigation/Home/For+Profess ionals/For+Professionals.aspx. 2016. (Last accessed September 22, 2016).

9. Palliative Care Tools: www.cancercare.on.ca/toolbox/pall caretools/. (Last accessed September 19, 2016).

10. Education in Palliative and End-of-Life Care: www.epec .net. (Last accessed September 17, 2016).

11. Backgrounder: Palliative Care (Medical) Education: www .cspcp.ca/wp-content/uploads/2014/10/Backgrounder-Palli ative-Medicine-Education.pdf. 2015. (Last accessed September 23, 2016).

12. Schroder C, Heyland D, Jiang X, et al.: Educating medical residents in end-of-life care: Insights from a multicenter survey. J Palliat Med 2009;12:459-470.

13. Boet S, Sharma S, Goldman J, Reeves S: Review article: Medical education research: An overview of methods. Can J Anaesth 2012;59:159-170.

14. Zendejas B, Brydges R, Wang AT, Cook DA: Patient outcomes in simulation-based medical education: A systematic review. J Gen Intern Med 2013;28:1078-1089.

15. von Gunten CF, Twaddle M, Preodor M, et al.: Evidence of improved knowledge and skills after an elective rotation in a hospice and palliative care program for internal medicine residents. Am J Hosp Palliat Care 2005;22:195203.

16. Duong PH, Zulian GB: Impact of a postgraduate six-month rotation in palliative care on knowledge and attitudes of junior residents. Palliat Med 2006;20:551-556.

17. Quinn K, Hudson P, Ashby M, Thomas K: "Palliative care: The essentials": Evaluation of a multidisciplinary education program. J Palliat Med 2008;11:1122-1129.

18. Stanton RN: Ambulatory hospice training in family medicine residency. J Palliat Med 2003;6:782-785.

19. Tiernan E, Kearney M, Lynch AM, et al.: Effectiveness of a teaching programme in pain and symptom management for junior house officers. Support Care Cancer 2001;9:606610.
20. Yacht AC, Suglia SF, Orlander JD: Evaluating an end-oflife curriculum in a medical residency program. Am J Hosp Palliat Care 2006;23:439-446.

21. Liao S, Amin A, Rucker L: An innovative, longitudinal program to teach residents about end-of-life care. Acad Med 2004;79:752-757.

22. Pulsford D, Jackson G, O'Brien T, et al.: Classroom-based and distance learning education and training courses in endof-life care for health and social care staff: A systematic review. Palliat Med 2013;27:221-235.

23. Ellman MS, Fortin AH, Putnam A, Bia M: Implementing and evaluating a four-year integrated end-of-life care curriculum for medical students. Teach Learn Med 2016; 28:229-239.

24. Bergman J, Lorenz KA, Ballon-Landa E, et al.: A scalable web-based module for improving surgical and medical practitioner knowledge and attitudes about palliative and end-of-life care. J Palliat Med 2015;18:415-420.

25. Dy SM, Hughes M, Weiss C, Sisson S: Evaluation of a web-based palliative care pain management module for housestaff. J Pain Sympt Manage 2008;36:596-603.

26. Pelayo-Alvarez M, Perez-Hoyos S, Agra-Varela Y: Clinical effectiveness of online training in palliative care of primary care physicians. J Palliat Med 2013;16:1188-1196.

27. Critchley PP, Grantham M, Plach N, et al.: An evaluation of the use of and satisfaction with the Palliative Care Pain and Symptom Pocket Card. J Palliat Care 2002;18:307311.

28. Mikhael J, Baker L, Downar J: Using a pocket card to improve end-of-life care on internal medicine clinical teaching units: A cluster-randomized controlled trial. J Gen Intern Med 2008;23:1222-1227.

29. Chung H-O, Oczkowski SJ, Hanvey L, et al.: Educational interventions to train healthcare professionals in end-of-life communication: A systematic review and meta-analysis. BMC Med Educ 2016;16:131.

30. Berkhof M, van Rijssen HJ, Schellart AJ, et al.: Effective training strategies for teaching communication skills to physicians: An overview of systematic reviews. Patient Educ Couns 2011;84:152-162.

31. Fallowfield L, Jenkins V, Farewell V, et al.: Efficacy of a Cancer Research UK communication skills training model for oncologists: A randomised controlled trial. Lancet 2002;359:650-656.

32. Bays AM, Engelberg RA, Back AL, et al.: Interprofessional communication skills training for serious illness: Evaluation of a small-group, simulated patient intervention. J Palliat Med 2014;17:159-166.

33. Curtis JR, Back AL, Ford DW, et al.: Effect of communication skills training for residents and nurse practitioners on quality of communication with patients with serious illness: A randomized trial. JAMA 2013;310: 2271-2281.

34. Downar J, McNaughton N, Abdelhalim T, et al.: Standardized patient simulation versus didactic teaching alone for improving residents' communication skills when discussing goals of care and resuscitation: A randomized controlled trial. Palliat Med 2016;31:130-139.

35. Tulsky JA, Fischer GS, Rose MR, Arnold RM: Opening the black box: How do physicians communicate about advance directives? Ann Intern Med 1998;129:441-449.

36. Tulsky JA, Chesney MA, Lo B: See one, do one, teach one? House staff experience discussing do-not-resuscitate orders. Arch Intern Med 1996;156:1285-1289. 
37. Tulsky JA, Chesney MA, Lo B: How do medical residents discuss resuscitation with patients? J Gen Intern Med 1995; 10:436-442.

38. Back AL, Arnold RM, Baile WF, et al.: Faculty development to change the paradigm of communication skills teaching in oncology. J Clin Oncol 2009;27:1137-1141.

39. Holmboe ES, Ward DS, Reznick RK, et al.: Faculty development in assessment: The missing link in competencybased medical education. Acad Med 2011;86:460-467.

40. Veloski J, Boex JR, Grasberger MJ, et al.: Systematic review of the literature on assessment, feedback and physicians' clinical performance: BEME Guide No. 7. Med Teach 2006;28:117-128.

41. Delva D, Sargeant J, Miller S, et al.: Encouraging residents to seek feedback. Med Teach 2013;35:e1625-e1631.

42. Steinert Y, Mann K, Centeno A, et al.: A systematic review of faculty development initiatives designed to improve teaching effectiveness in medical education: BEME Guide No. 8. Med Teach 2006;28:497-526.

43. Kadlec H, Hollander MJ, Clelland C, et al.: Family physicians enhance end-of-life care: Evaluation of a new continuing medical education learning module in British Columbia. BMC Med Educ 2015;15:119.

44. Gillett K, Bryan L: "Quality End of Life Care for All" (QELCA): The national rollout of an end-of-life workforce development initiative. BMJ Support Palliat Care 2016;6: 225-230.
45. Based on Core Competencies: www.abms.org/boardcertification/a-trusted-credential/based-on-core-competencies/. (Last accessed September 22, 2016).

46. Connolly M, Charnley K, Regan J: A Review of Palliative Care Competence Frameworks: Prepared for the Palliative Care Competency Framework Development Project Steering Group. Dublin: Health Service Executive, 2012.

47. Myers J, Krueger P, Webster F, et al.: Development and validation of a set of palliative medicine entrustable professional activities: Findings from a mixed methods study. J Palliat Med 2015;18:682-690.

48. Rocker G, Downar J, Morrison RS: Palliative care for chronic illness: Driving change. CMAJ 2016;188:E493-E498.

49. Turner M, Payne S, O'Brien T: Mandatory communication skills training for cancer and palliative care staff: Does one size fit all? Eur J Oncol Nurs 2011;15:398-403.

Address correspondence to: James Downar, MDCM, MHSc (Bioethics), FRCPC

Department of Medicine University of Toronto

200 Elizabeth Street, 11PMB-195

Toronto, Ontario M5G 2 C4

Canada

E-mail: james.downar@utoronto.ca 